\title{
Deflection and frequency monitoring of the Forth Road Bridge, Scotland, by GPS
}

1 Gethin W. Roberts BEng, PhD

Dean of Science and Engineering, Faculty of Science and Engineering, University of Nottingham Ningbo China, Ningbo, China

2 Christopher J. Brown BSC

Reader, Applied Mechanics, School of Engineering and Design, Brunel University, Uxbridge, UK

3 Xiaolin Meng PhD

Associate Professor and RCUK Fellow, Institute of Engineering Surveying and Space Geodesy, University of Nottingham Innovation Park, Nottingham, UK
4 Oluropo Ogundipe BSC, PhD

Research Fellow, Institute of Engineering Surveying and Space Geodesy, University of Nottingham Innovation Park, Nottingham, UK

5 Christopher Atkins BA, MSC

MSc graduate, Institute of Engineering Surveying and Space Geodesy, University of Nottingham Innovation Park, Nottingham, UK

6 Barry Colford BSC

Chief Engineer and Bridge Master, Forth Estuary Transport Authority, South Queensferry, West Lothian, UK
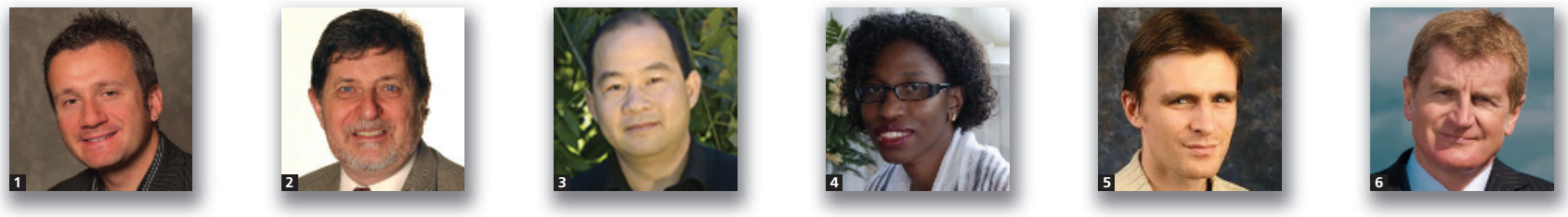

The use of carrier phase kinematic GPS (global positioning system) has evolved into a reliable technique to measure both the three-dimensional magnitudes and frequencies of movements of structures. Techniques have been developed that tackle errors caused by multipath, tropospheric delay and issues relating to satellite geometry. GPSderived movements compare well with data from both design predictions and structural models. Results from field trials carried out on the Forth Road Bridge are presented. This paper brings together key results that outline the procedure as well as a series of new data that indicate other potential applications. GPS data were collected continuously over a period of $46 \mathrm{~h}$ at a minimum rate of $10 \mathrm{~Hz}$. During the trials wind speed, wind direction, relative humidity and temperature were also recorded. Frequently there was very heavy traffic flow, and at one point a special load (a 100-t lorry) passed over simultaneously to the heavy daytime flow of traffic. Data from a planned load trial during a brief bridge closure are reported and compared with the limited results available from a finite element model. Measured vibration frequencies are also computed from GPS data and compared with those given in the literature. In addition, results indicating the change in structural characteristics are also presented - in particular changes of mass associated with changes in traffic loading are observed. The results show the performance of GPS as it has developed in recent years, and that it can now reliably be used as a significant part of structural health monitoring schemes, giving both the magnitude of quasi-static deflections in known time periods and hence the frequency of dynamic movements of structures.

\section{Introduction}

GPS (global positioning system) monitoring of major infrastructure projects, notably suspension bridges, continues to develop (Ashkenazi et al., 1996; Ashkenazi and Roberts, 1997; Barnes et al., 2003; Brown et al., 1999, 2006, 2008; Dan et al., 2008, Fujino et al., 2000; Guo et al., 2000; Meng, 2002; Meng et al., 2005, 2007a; Roberts et al., 2004, 2008; Wong, 2007).

\subsection{GPS measurements}

GPS was originally designed to work by measuring the time it takes binary codes, modulated onto carrier frequencies, to reach a GPS antenna from satellites with known coordinates orbiting the earth some $20000 \mathrm{~km}$ above its surface. There are two carrier frequencies, known as L1 and L2, with wavelengths of approximately $19 \mathrm{~cm}$ and $24 \mathrm{~cm}$, onto which are modulated 
Bridge Engineering

Volume 165 Issue BE2
Deflection and frequency

monitoring of the Forth Road

Bridge, Scotland, by GPS

Roberts, Brown, Meng, et al. the coarse acquisition code (C/A code) onto L1, and the precise code ( $\mathrm{P}$ code, also known as the $\mathrm{Y}$ code) on both L1 and L2. Satellites are currently being launched to replace the existing satellites when they are no longer working. These current replacement satellites known as block IIRM have a civilian code ( $\mathrm{C}$ code) on $\mathrm{L} 2$ in addition to the $\mathrm{C} / \mathrm{A}$ and $\mathrm{P}$ codes. Future block IIF satellites have an L5 carrier frequency as well as a whole range of codes on all three frequencies. Currently the C/A code is only widely available for non-US military use, but the $\mathrm{C}$ code and L5 carrier will make a wider range of signals available for all. The main advantage is that the errors induced onto these radio frequencies by the ionosphere can be eliminated when using multiple frequencies (Hancock et al., 2009; HofmannWelenhoff et al., 2001; Leick, 2004).

The carrier phase itself is also used for precise range measurements. The phase of the carrier signal can be measured to submillimetre resolution. This observable is mainly used for survey purposes, whereby a carrier phase-enabled GPS receiver is positioned relative to another similar receiver located over a survey marker with a known three-dimensional (3D) coordinate. Millimetric relative positioning is possible through using these observations (Hancock et al., 2009). However, even though the carrier phase can be measured to submillimetre resolution, in order to be able to use this precise measurement, a whole number of carrier wavelengths, also known as the integer ambiguity, needs to be added onto this measurement to result in the true range. Various techniques have been developed that are used to calculate the integer ambiguity values for the various satellites used (Leick, 2004).

The use of carrier phase GPS enables 3D movements of bridges to be measured at precise times with at least subcentimetre precision and relative accuracies to the reference GPS receiver. Due to the fact that each $3 \mathrm{D}$ coordinate is associated with a precise time, the frequency of the movement can also be derived. The work has evolved in data analysis to include multipath mitigation (Roberts et al., 2002), using the internet to transfer GPS data (Dodson et al., 2004) and in GPS processing, both using single and dual frequency code/carrier data (Cosser et al., 2003). Finite element model (FEM) predictions of structural behaviour have been successfully validated using GPS results (Brown et al., 1999).

Measuring deflections of large-scale relatively flexible structures is technically challenging, but GPS is particularly well suited. Nevertheless, care must be taken with the position of both receivers and reference stations. It has been shown (Brownjohn et al., 2004; Brownjohn, 2005) that measuring movements of tall buildings is always prone to error because it is rarely possible to have reference stations located at similar altitudes to the monitoring GPS receivers and thus with the same tropospheric interference patterns as the receivers. Nevertheless, the minimal importance of vertical movement in multistorey buildings makes it a viable technique for lateral dynamics.

The Humber Bridge was the first bridge in the UK to be used as a test-bed for GPS trials. In 1996, Brunel University was commissioned by the Humber Bridge Board to create a FEM of the bridge (Karuna et al., 1997). Following this, the group at the University of Nottingham carried out initial bridge monitoring trials on the bridge and the displacement data were then used to validate the FEM (Karuna et al., 1997, 1998). The potential of the technique for measuring frequency was identified and reported at this stage. Work on the London Millennium Footbridge before its structural modification has also been reported (Roberts et al., 2006), and to date four major UK bridges have been monitored by the authors, with a further three to be monitored soon.

The major GPS assessment of the Forth Road Bridge is the subject of this paper. The paper mainly details the results of a trial carried out on the bridge in Scotland in February 2005. The Forth Road Bridge (Figure 1) crosses the Firth of Forth and links the north of Scotland with Edinburgh and the south, carrying the A90 road. It has an overall length of $2.5 \mathrm{~km}$ and a main span length of $1005 \mathrm{~m}$. It was opened to traffic in 1964, and brought to an end a 800 -year history of ferryboat service across the river at Queensferry. It is approximately parallel to and upstream (west by approximately $800 \mathrm{~m}$ ) of the wellknown Forth Railway Bridge. The road bridge runs at $3^{\circ}$ from north. The construction of the bridge was well described shortly after its completion (Anderson et al., 1965). It has a stiffening truss underneath the deck, and significant torsional restraint is provided at each end of the deck. Additional structural stiffening has been added to the towers subsequent to original construction.

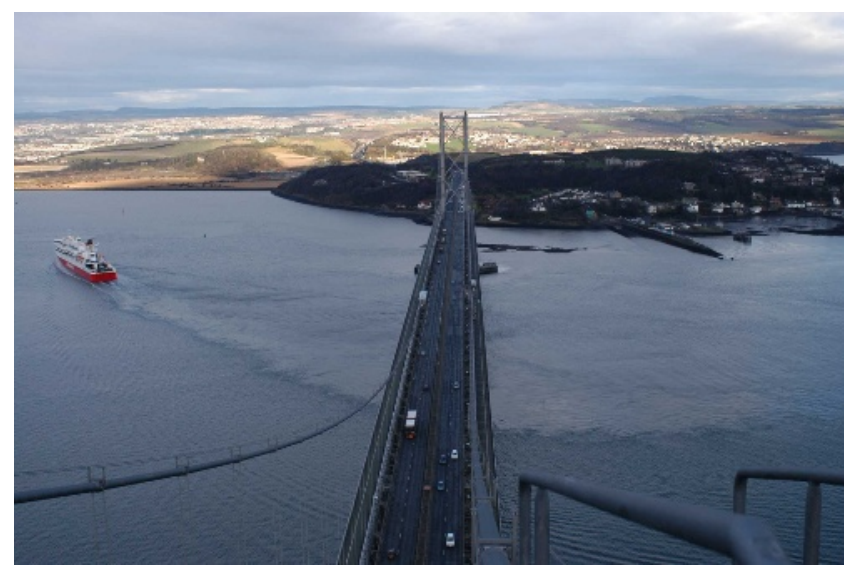

Figure 1. The Forth Road Bridge, taken from the top of the southern support tower 


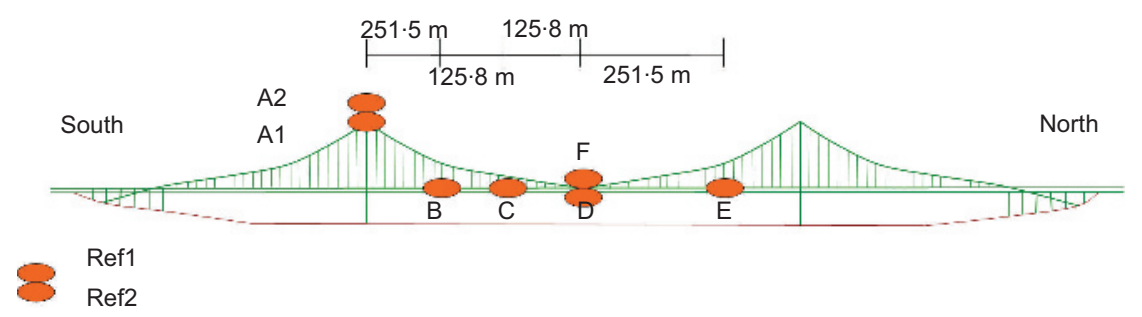

Figure 2. The GPS receiver locations on the bridge

Traffic has steadily increased over this bridge, from 4 million vehicles in 1964 to over 23 million in 2002. In 1964 the heaviest unrestricted commercial vehicles weighed $24 \mathrm{t}$; the current limit is $44 \mathrm{t}$. There is a significant tidal traffic flow from north to south in the morning peak and in the reverse direction in the evening. Until recently the toll booths at the southern approach meant that significant volumes of traffic were stationary on the southbound carriageways in the morning peak period, but a recent decision by the local Scottish parliament has removed tolls and thus reduced some of the peak load due to traffic.

Unconnected to this, there has been an inspection of the main suspension cables following anxiety about the corroded state of cables in suspension bridges of a similar age and design. While those surveys are ongoing it should be emphasised that the work described below is not part of that study.

\section{Methods and measurements on the Forth Road Bridge}

\subsection{Instrumentation}

During a 46-h period from 8 to 10 February 2005, the authors and staff from the Institute of Engineering Surveying and Space Geodesy (IESSG) at the University of Nottingham gathered data continuously from GPS receivers located on the bridge. To ensure continuity of data two reference GPS stations were used, located on the southern end viewing platform of the north-south orientated bridge. A further five GPS receivers were fixed to the bridge deck and two GPS receivers were located on top of the southern support tower. This limited number was governed by resources available for the trial. In addition, a high accuracy INS, POS-RS inertial measurement unit manufactured by Applanix (Richmond Hill, Canada) was also located upon the bridge. The use of INS (inertial navigation systems) for bridge deformation monitoring is discussed elsewhere (Hide et al., 2005).

Of the seven receivers on the bridge, four were located at the quarter, three-eighths, half and three-quarter span from the southern end on the east side of the deck to produce a displaced profile, while a fifth was located at the midspan on the west side of the bridge. A further two receivers were located on top of the two towers at the south end of the bridge. The GPS receivers on the bridge were coordinated relative to the reference receivers. The receiver layout is shown in Figure 2.

All the GPS receivers gathered data for the test period at a minimum rate of $10 \mathrm{~Hz}$. Table 1 shows a list of the receivers and antennas used in the trial. Data collection was interrupted only to download data from storage cards - a process that took approximately $1 \mathrm{~min}$. Clamps were fabricated by the Forth Estuary Transport Authority (FETA) to allow the GPS antennas to be attached to the bridge handrail, but constructed in such a way as not to pose a danger to passing pedestrians or

\begin{tabular}{lllll}
\hline Location & Receiver type & Antenna type & Data rate $(\mathrm{Hz})$ & Location \\
\hline B & Leica SR530 & AT503 & 10 & E 1/4 span \\
C & Leica SR530 & AT503 & 10 & E 3/8 span \\
D & Leica SR530 & AT503 & $1 / 2$ span \\
E & POS RS & NovAtel 600 & 10 & E 3/4 span \\
F & Leica GX1230 & AT504 & 20 & W 1/2 span \\
A1 & Leica SR530 & AT504 & 10 & Tower west (S) \\
A2 & Leica SR510 & AT501 & 10 & Tower east (S) \\
R1 & Leica SR530 & AT503 & 10 & Reference \\
R2 & Leica SR530 & AT503 & 10 & Reference
\end{tabular}

Table 1. Antennas and receivers: location, type and characteristics 
Deflection and frequency

monitoring of the Forth Road

Bridge, Scotland, by GPS

Roberts, Brown, Meng, et al.

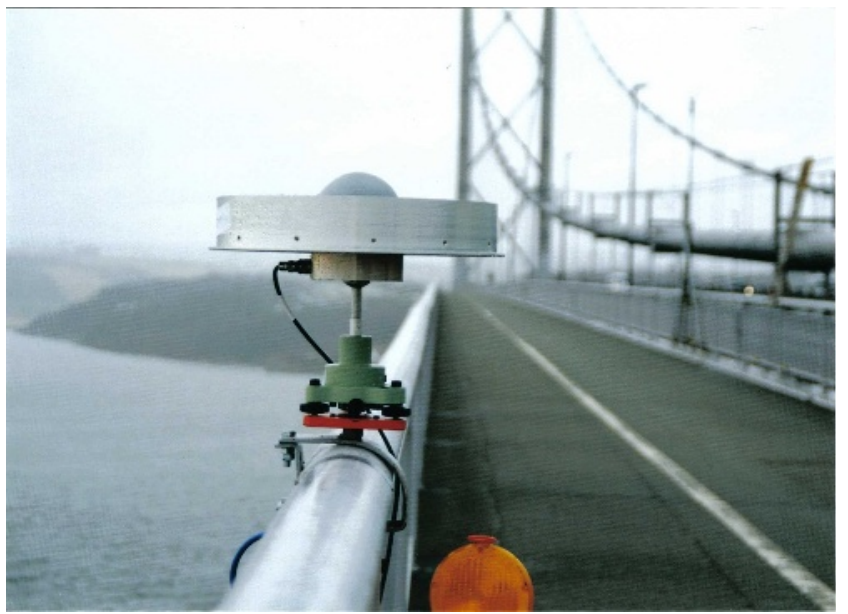

Figure 3. A Leica choke-ring antenna located on the bridge handrail using a dedicated clamp

cyclists. AC power was supplied at each receiver site. Figure 3 illustrates a Leica Geosystems (Milton Keynes, UK) chokering antenna attached to the bridge handrail. All antennas at locations B-F on the bridge were fixed to the outer handrail in this manner.

Four types of survey-grade GPS receivers were used. These included single and dual frequency code and carrier-phase receivers of the same generation, as well as a Leica GX1230, which was then the latest generation of dual frequency receivers. The POS-RS receiver was a NovAtel (Calgary, Canada) dual frequency OEM4 GPS receiver and was linked directly to an Applanix POS-RS inertial measurement unit (Hide et al., 2005). A number of GPS antennas were used to investigate various aspects of antenna performance. These include the Leica AT 501 single frequency antenna, AT 503; a dual frequency lightweight choke-ring antenna, a Leica AT 504; a dual frequency heavyweight choke-ring antenna as well as the NovAtel GPS 600 series antenna. A weather station was installed at midspan on the western footway to gather the temperature, relative humidity, wind speed and wind direction continuously.

The Ordnance Survey (OS) of Great Britain has over 100 'active station' GPS receivers located around the UK (Ordnance Survey, 2008). These stations gather data at $1 \mathrm{~Hz}$, but then the data are made available to the public at a $15 \mathrm{~s}$ epoch rate by means of the OS web site. In addition to this, the OS recently established their own network RTK GPS system in the UK. During the trials, the GPS data from a number of OS stations located adjacent to Edinburgh were gathered at a rate of $1 \mathrm{~Hz}$ for the IESSG in order to use these as a comparison with the bridge data processed relative to the reference stations next to the bridge.
GPS receivers gathered the data to post-process using Leica's Geo Office software in an on-the-fly manner. On-the-fly carrier phase ambiguity resolution is a data processing technique that resolves the integer ambiguities of the carrier phase while the GPS antenna is moving (Leick, 2004). Staff were continuously present sitting in cars at each receiver location on the deck, as the security of the receivers was a concern on an open access footpath.

\subsection{Bridge loading}

During the trials, wind gusts of up to $80 \mathrm{~km} / \mathrm{h}$ were experienced. Traffic loading could be very heavy, especially at rush hour times in early morning and evening when tidal traffic flow was evident. In addition, coincidentally during the trials, a single 100-t lorry passed over the bridge.

A series of known load trials was carried out with two 40-t lorries, equipped with differential GPS to ascertain their location; the bridge was closed to other traffic for this trial and produced the most controlled load condition of all the trials.

\section{Accuracy checks of GPS data}

The data were processed in an on-the-fly manner using Leica GeoOffice 3.0. Once processed, the resulting files consisted of 3D coordinate data at a rate of $10 \mathrm{~Hz}$, in WGS84 (GPS coordinates) with the corresponding precise time. The data were converted into a coordinate system relative to the bridge, giving lateral (approximately E-W), longitudinal (along the direction of the bridge equals direction of travel) and vertical displacements.

\subsection{Zero baseline tests; accuracy and resolution of kinematic GPS}

One method of establishing the precision, resolution and resulting accuracies of the GPS receivers and software used is through gathering and processing data from a zero baseline. The GPS processing technique used during these tests is called kinematic GPS, and uses an on-the-fly integer ambiguity search technique. The carrier phase data at the rover end, in the case of this paper on the bridge, is processed relative to a reference GPS receiver, in the case of this paper located on a tripod adjacent to the bridge.

A zero baseline consists of two GPS receivers simultaneously attached to a single GPS antenna through the use of a cable splitter. This means that all the external error sources such as those caused by the ionosphere, troposphere, multipath, satellite and receiver clocks are eliminated, as they are identical for both receivers connected to the same antenna, resulting in data that are a true reflection of the GPS receiver's resolution, as well as the relative accuracy of the GPS receiver relative to the reference GPS receiver. The resulting noise is the noise within the GPS receiver as well as the resolution of the carrier phase signal, thus showing the potential accuracies of the GPS results. 


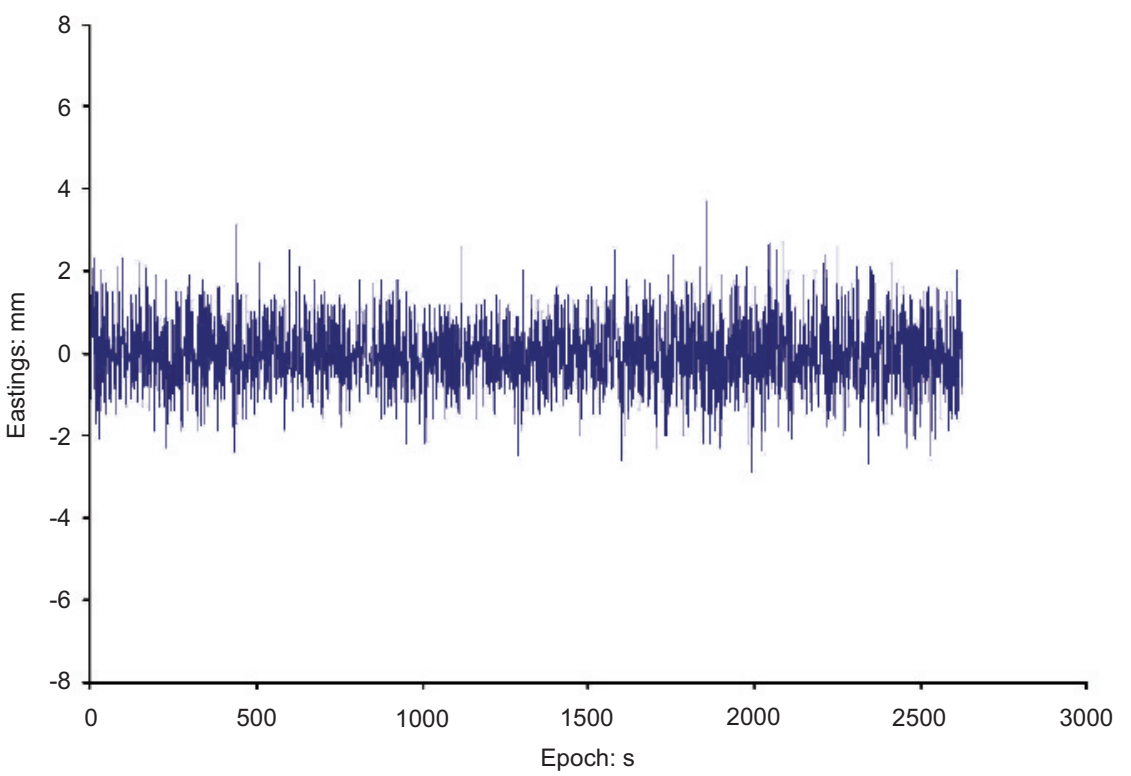

Figure 4. A scatter plot of the results from the SR530 GPS

receivers' zero baseline tests in the eastings direction

Two sets of tests were conducted. The first involved attaching two Leica SR530 dual frequency GPS receivers to the Leica AT504 choke-ring antenna used, 45 min of 1-s epoch interval data were gathered. Figures 4-9 illustrate the results in the eastings, northings and height direction, showing the scatter obtained over this time period, as well

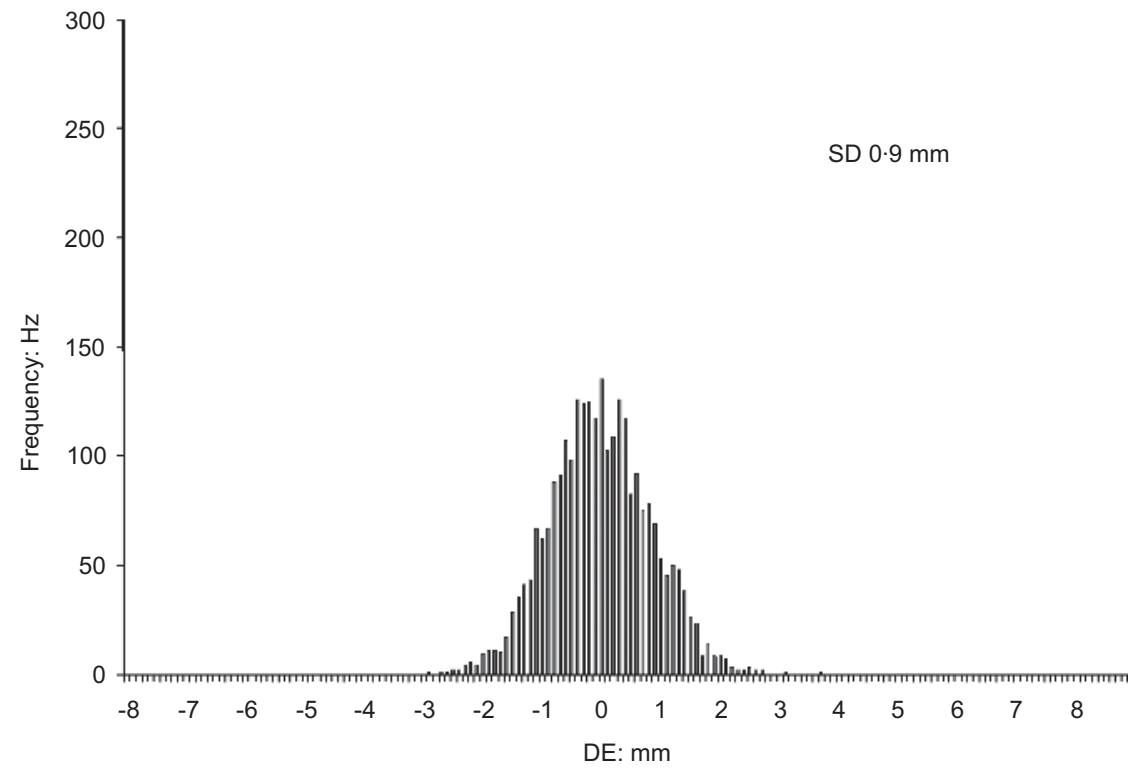

Figure 5. A histogram of the results from the SR530 GPS receivers' zero baseline tests in the eastings direction, showing a standard deviation of $0.9 \mathrm{~mm}$ 


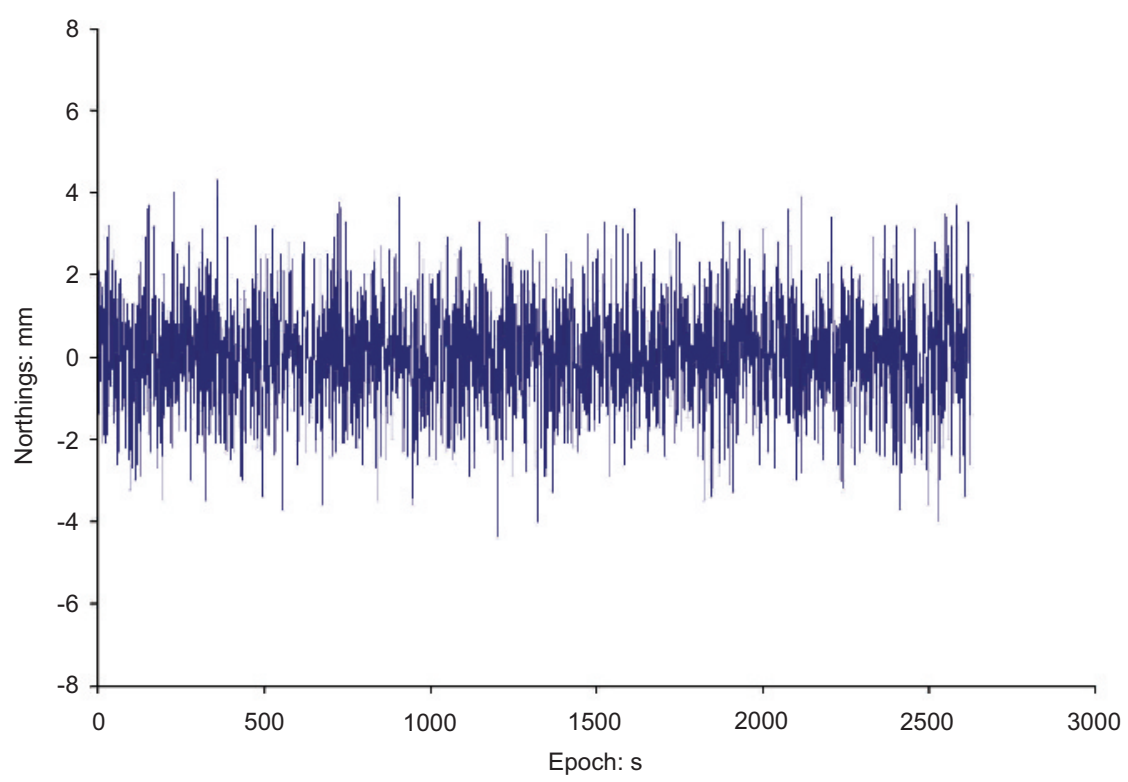

Figure 6. A scatter plot of the results from the SR530 GPS

receivers' zero baseline tests in the northings direction

as the histograms showing the scale of the scatter and standard deviations. The standard deviations can be seen to be $0.9 \mathrm{~mm}, 1.3 \mathrm{~mm}$ and $2.1 \mathrm{~mm}$ for the SR 530 GPS receiver in east, north and height directions, and $0.4 \mathrm{~mm}, 0.7 \mathrm{~mm}$ and $1.2 \mathrm{~mm}$ for the GX1230 GPS receiver in east, north and height directions, respectively.

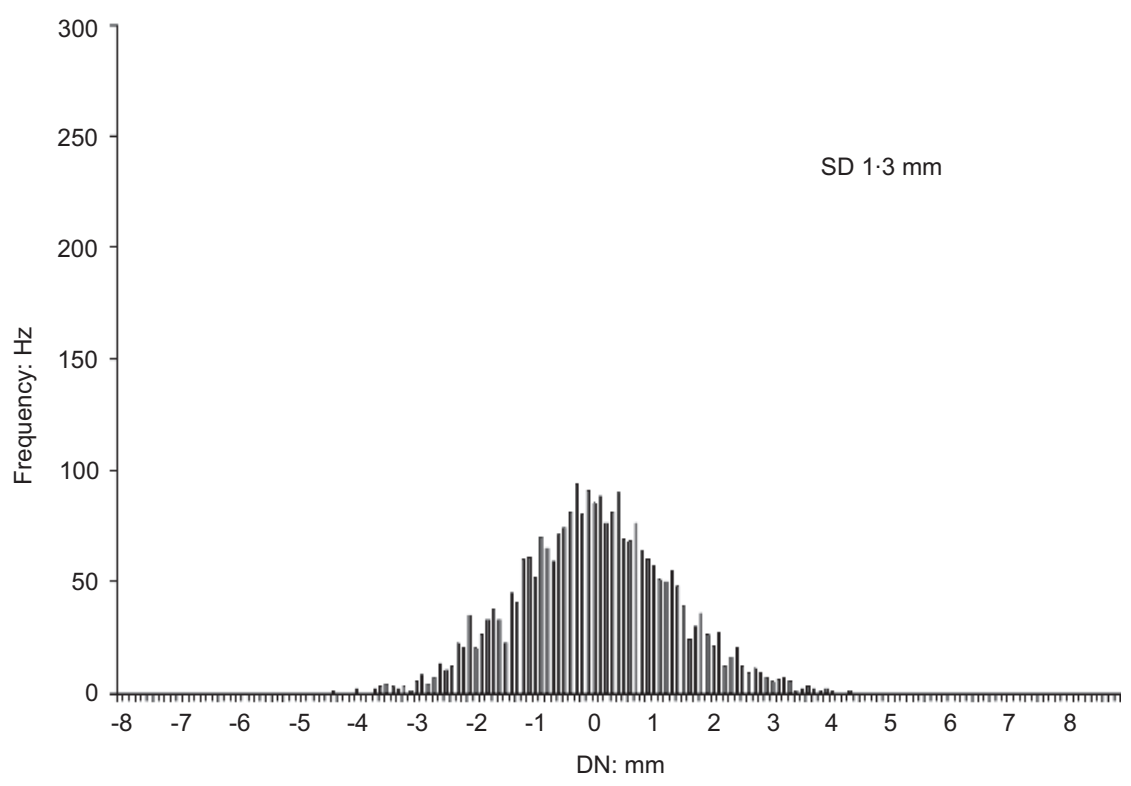

Figure 7. A histogram of the results from the SR530 GPS receivers' zero baseline tests in the northings direction, showing a standard deviation of $1.3 \mathrm{~mm}$ 


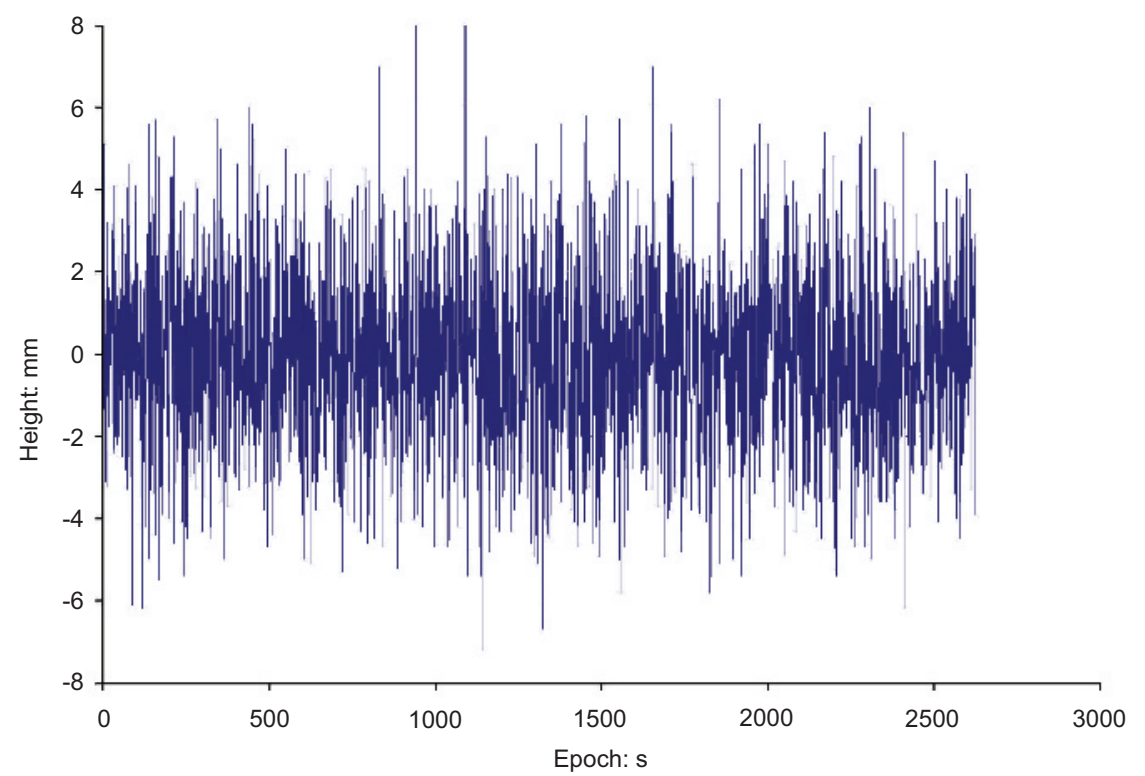

Figure 8. A scatter plot of the results from the SR530 GPS

receivers' zero baseline tests in the height direction

The second set of tests involved attaching two GX1230 dual frequency GPS receivers to the same choke-ring antenna. Again, 45 min of 1-s interval data were gathered, and again the results were processed with one of the receiver's data being used as a reference GPS receiver and the other as the rover. Figures 10-15 illustrate the scatter and histograms for these results in the eastings, northings and height directions.

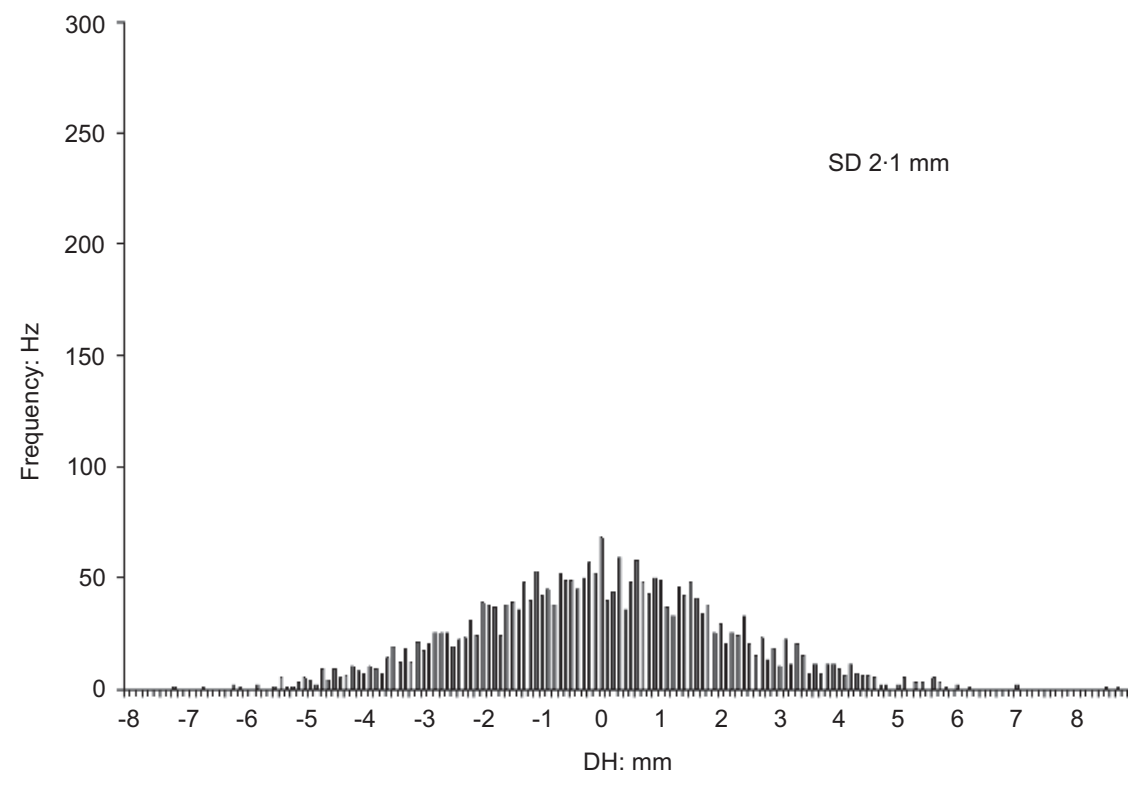

Figure 9. A histogram of the results from the SR530 GPS receivers' zero baseline tests in the height direction, showing a standard deviation of $2 \cdot 1 \mathrm{~mm}$ 


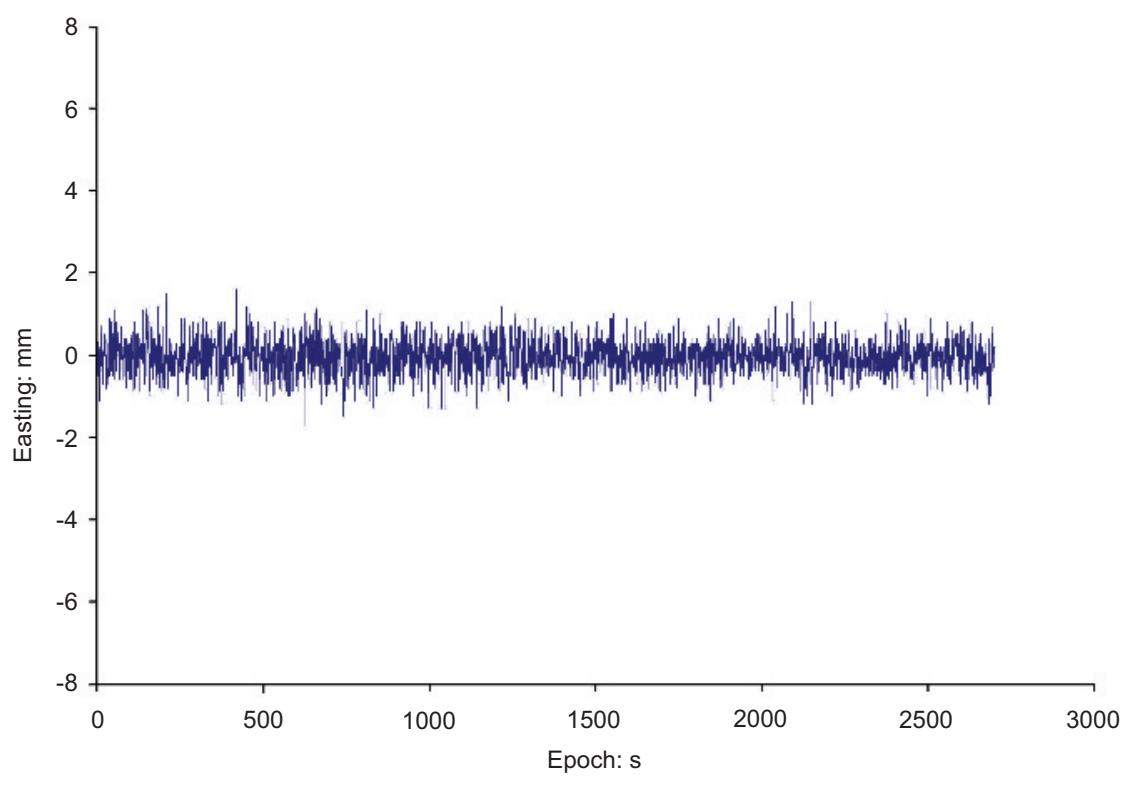

Figure 10. A scatter plot of the results from the GX1230 GPS

receivers' zero baseline tests in the eastings direction

It is evident from these results that the GX1230 GPS receiver is less noisy than the SR530, in addition to which, the GX1230 has a smaller spread of data in the histograms compared with the SR530, again showing a better concentration and quality of results. In fact, the SR530 generally seems to be twice as noisy as the GX1230 in all three components. This illustrates the magnitude of the GPS receivers' resolution and also shows the improvement in the quality of the GPS data from one generation of GPS receiver to the next.

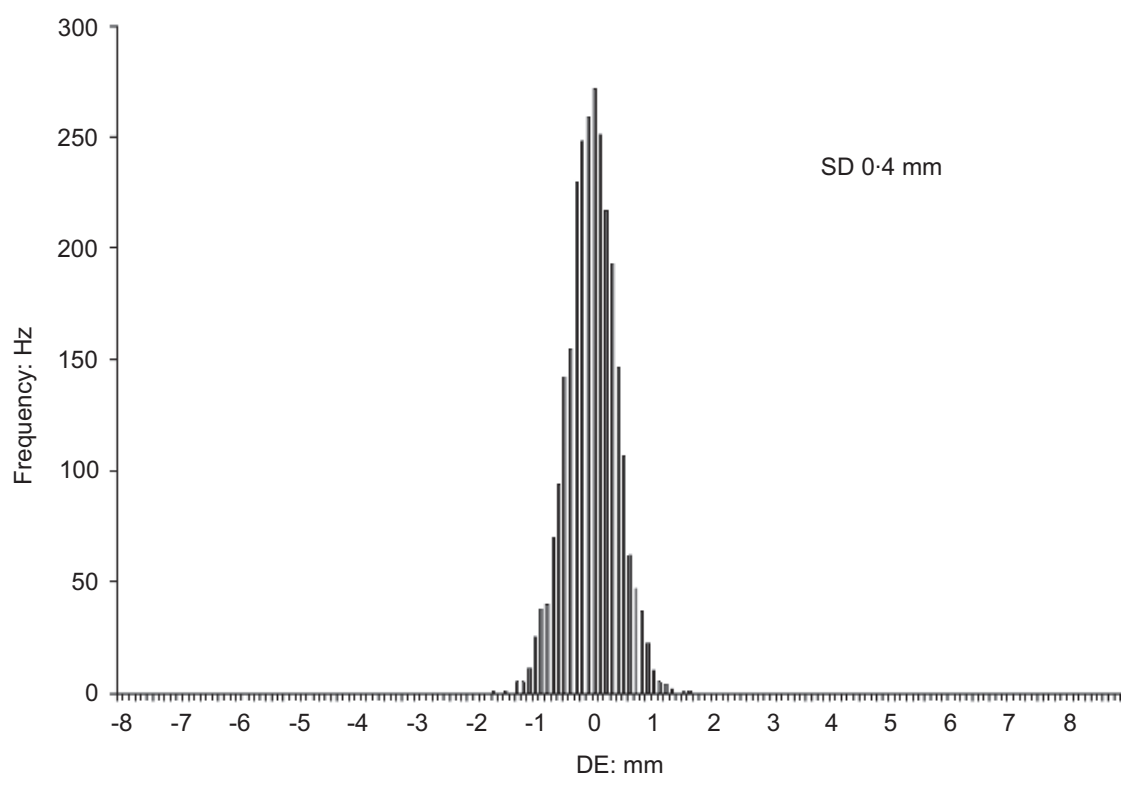

Figure 11. A histogram of the results from the GX1230 GPS

receivers' zero baseline tests in the eastings direction, showing a standard deviation of $0.4 \mathrm{~mm}$ 


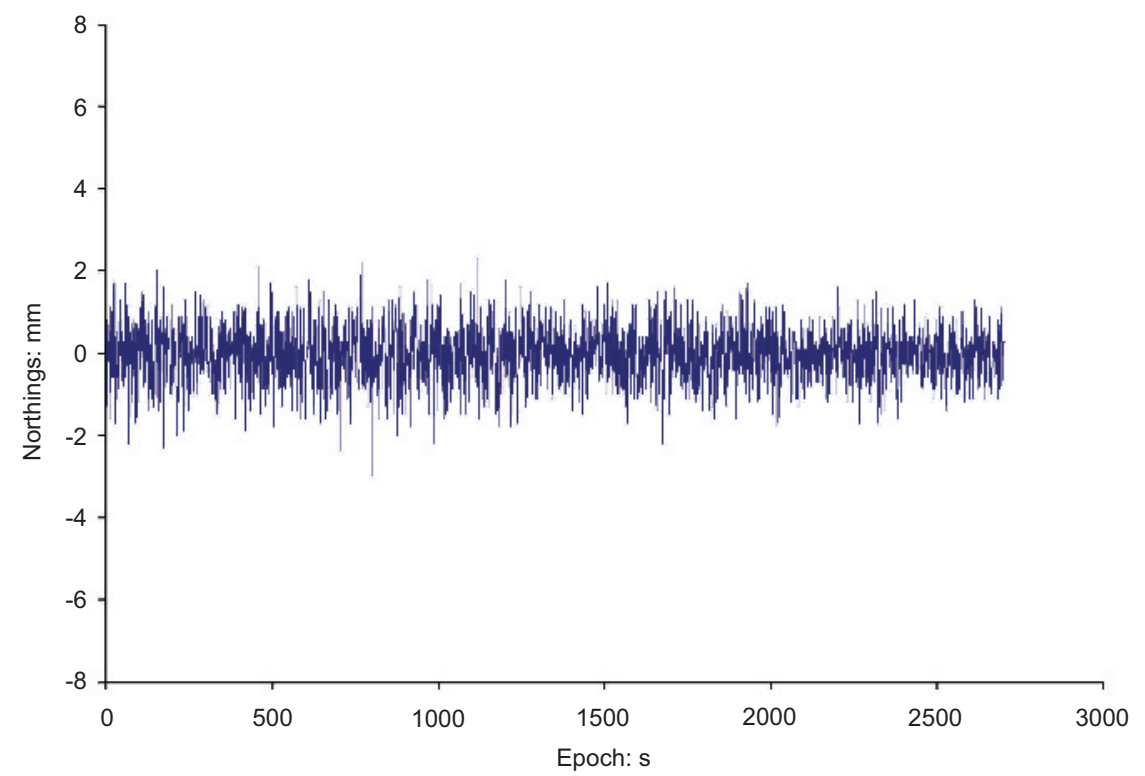

Figure 12. A scatter plot of the results from the GX1230 GPS

receivers' zero baseline tests in the northings direction

\section{Bridge results}

The GPS data were collected over $46 \mathrm{~h}$ at $10 \mathrm{~Hz}$ for seven GPS receivers on the bridge, relative to two reference GPS receivers adjacent to the bridge; this results in some 11 million data values. Wind speed, wind direction, temperature and relative humidity were also measured at

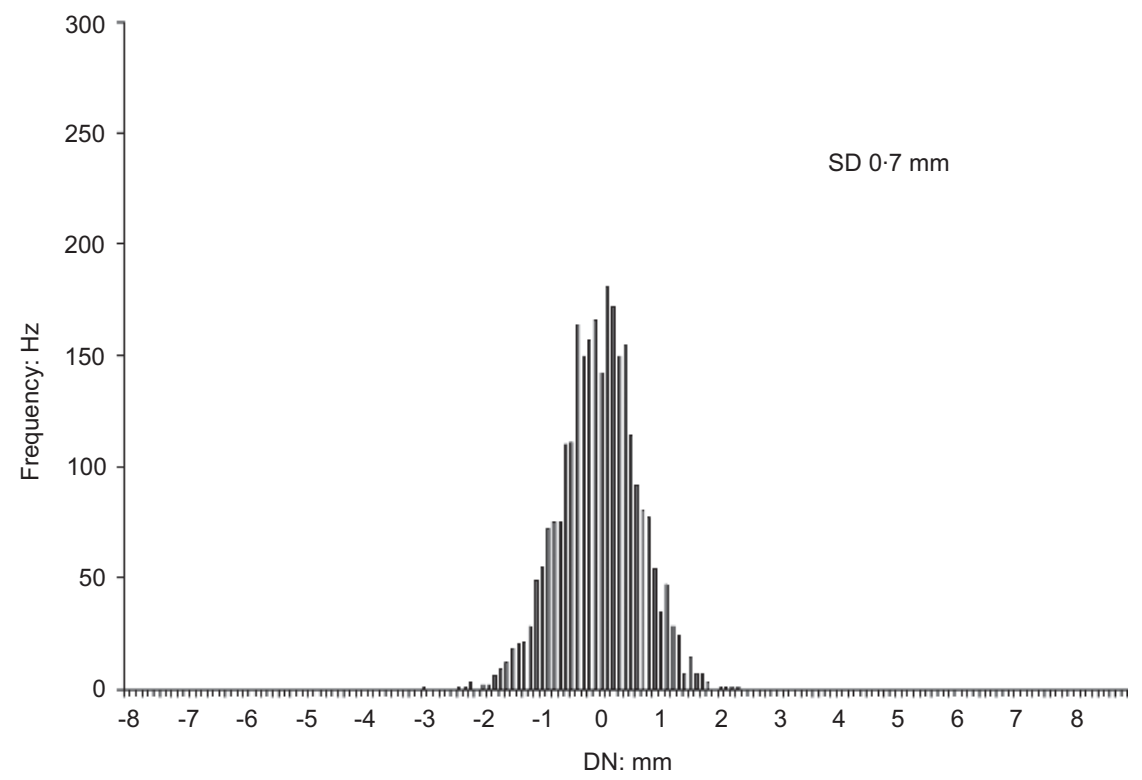

Figure 13. A histogram of the results from the GX1230 GPS

receivers' zero baseline tests in the northings direction, showing a standard deviation of $0.7 \mathrm{~mm}$ 


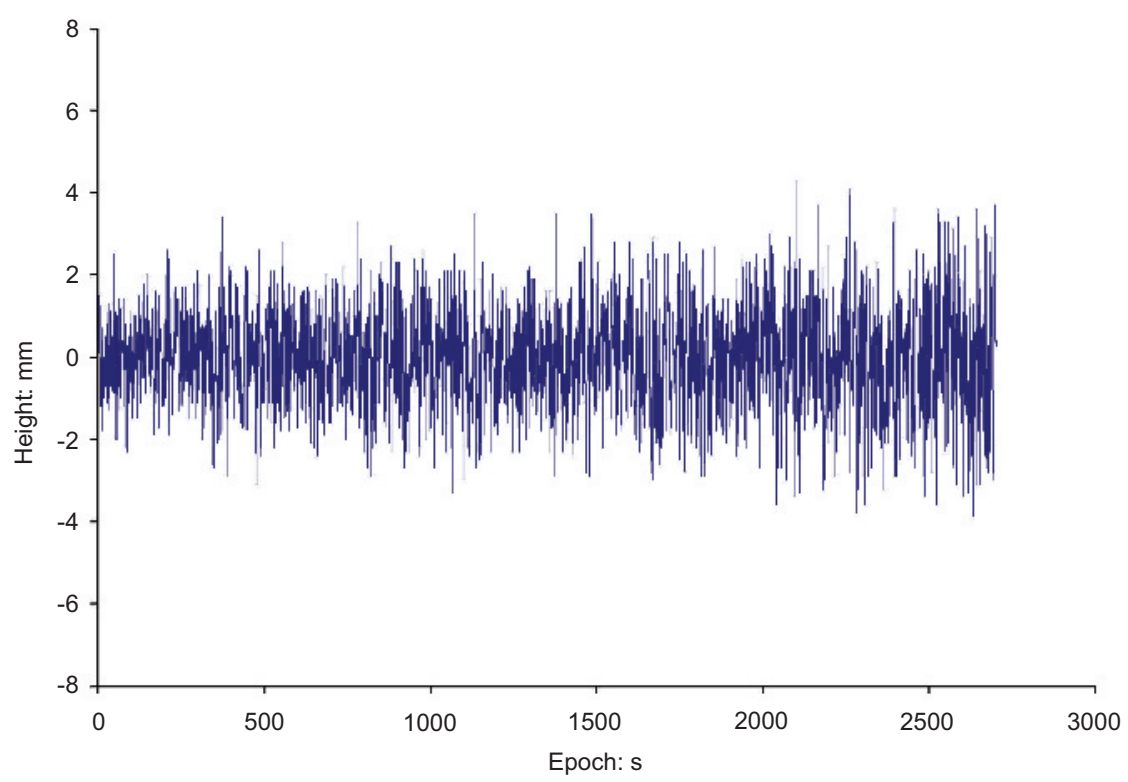

Figure 14. A scatter plot of the results from the GX1230 GPS

receivers' zero baseline tests in the height direction

$1 \mathrm{~Hz}$. To demonstrate the range of information available for health monitoring using GPS this paper provides a synopsis that presents: a sample of the raw data

a typical pattern of quasi-static 'engineering' deflections, and a extracted frequencies for a period when the structure was

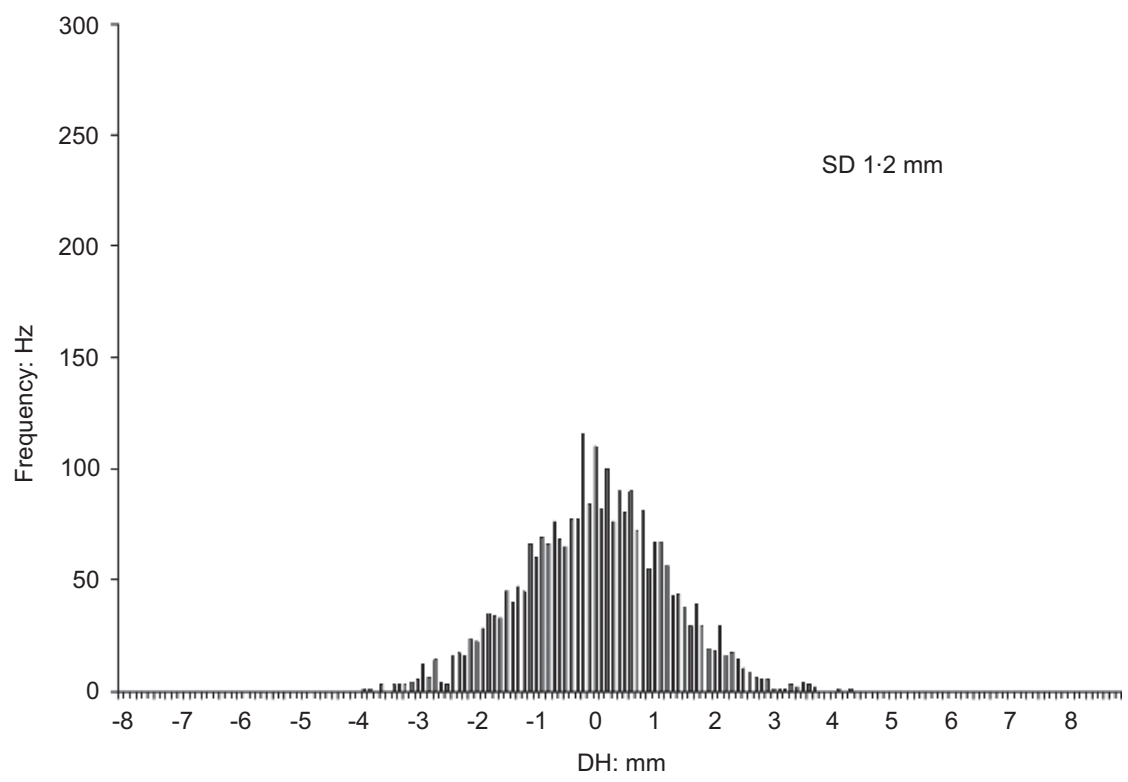

Figure 15. A histogram of the results from the GX1230 GPS receivers' zero baseline tests in the height direction, showing a standard deviation of $1.2 \mathrm{~mm}$ 


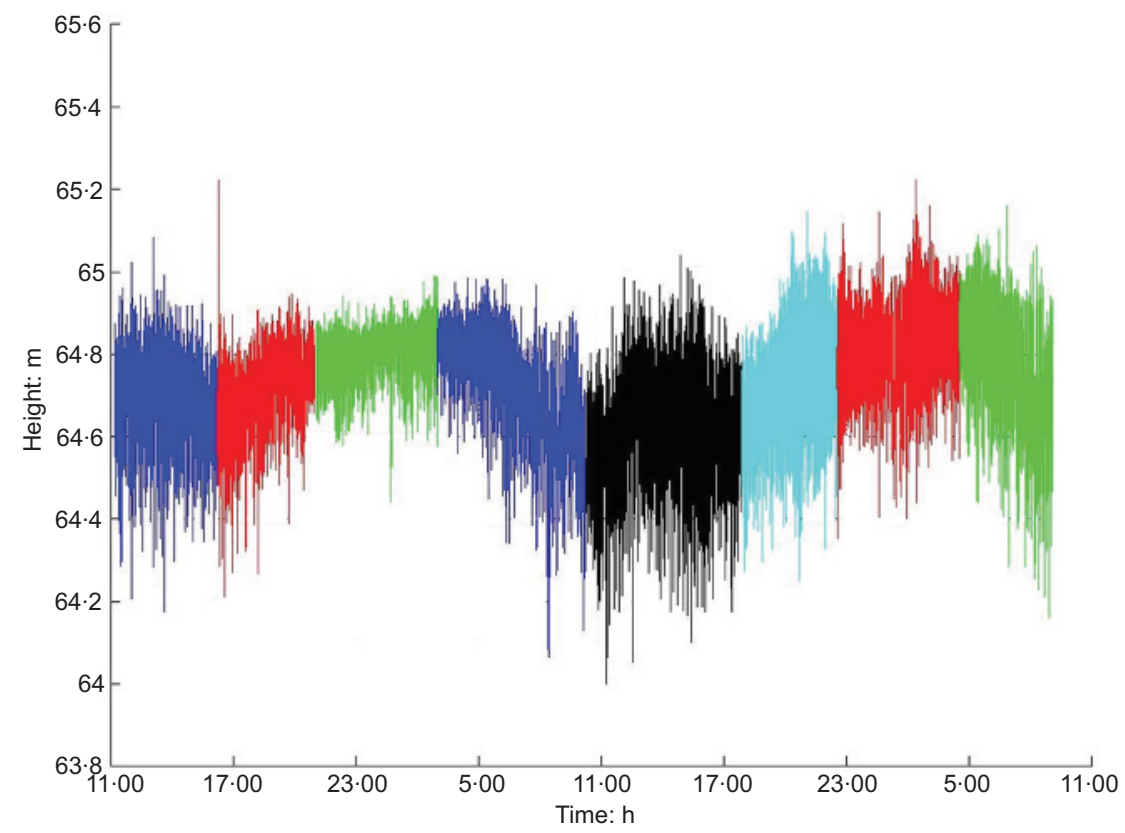

Figure 16. Height deflections of bridge site F over the 46-h trial (bridge coordinate system)

subject to wind action. (Note: the effect of wind on the structure has been reported fully elsewhere in Meng et al., 2007b).

Vertical movements of the deck are also presented under thermal action, while correlations between tower movements and bridge deck movements are confirmed.

For vertical displacements, the datum is taken as the average of the data above sea level and does not vary with time. For lateral and longitudinal displacements, a datum is required, and this can be an arbitrary position at an arbitrary point in time. The average of all readings taken at this datum has been used unless otherwise specified.

\subsection{Raw data}

Figures 16-18 illustrate the height, longitudinal and lateral displacements of the bridge over the whole 46 -h period for site F. The eight sessions of data processing - separated due to the limitation in the computer's capacity in handling large datasets - are shown. It should be noted that the three figures are plotted at maximum scale to show discrimination, but that these scales are significantly different. For longitudinal movement, Figure 17, the peak to peak is quite small - of the order of $\pm 40 \mathrm{~mm}$. From Figure 16 it can be seen that for the vertical movement the range is an order of magnitude larger - of the order of $\pm 400 \mathrm{~mm}$, while Figure 18 shows a significant range of lateral movements when wind effects are prevalent and lateral movements of the order of $1000 \mathrm{~mm}$ are discernible. These data are of limited practical value as they stand, but demonstrate the range of movements measured. However, further processing and analysis can make such data very useful.

\subsection{Measured quasi-static deflections: vertical load}

During the second night, two 40-t lorries were hired by FETA, accurately weighed and used as a controlled loading of the structure. These trials were carried out a couple of hours after the high winds experienced (see below) had subsided slightly, and during these specific trials the bridge was closed off to other traffic. The trials were carried out in the early hours of the morning, when the traffic flow was at a minimum, and the bridge only closed while the control lorries passed over and re-opened while they turned around before subsequent crossings. The lorries started the trials at the north end of the bridge, and travelled at 20 miles $/ \mathrm{h}(32 \mathrm{~km} / \mathrm{h})$ The manoeuvres were as follows:

(a) one lorry ran from north to south

(b) one lorry ran from south to midspan on the west side, stopped then the other lorry moved north to south

(c) one lorry moved from north to south and stopped at midspan, while the other moved south to north

(d) one lorry moved from south to north, and then both moved side by side north to south.

The overall movements experienced by the GPS receivers at different bridge sites in the height component for the whole 


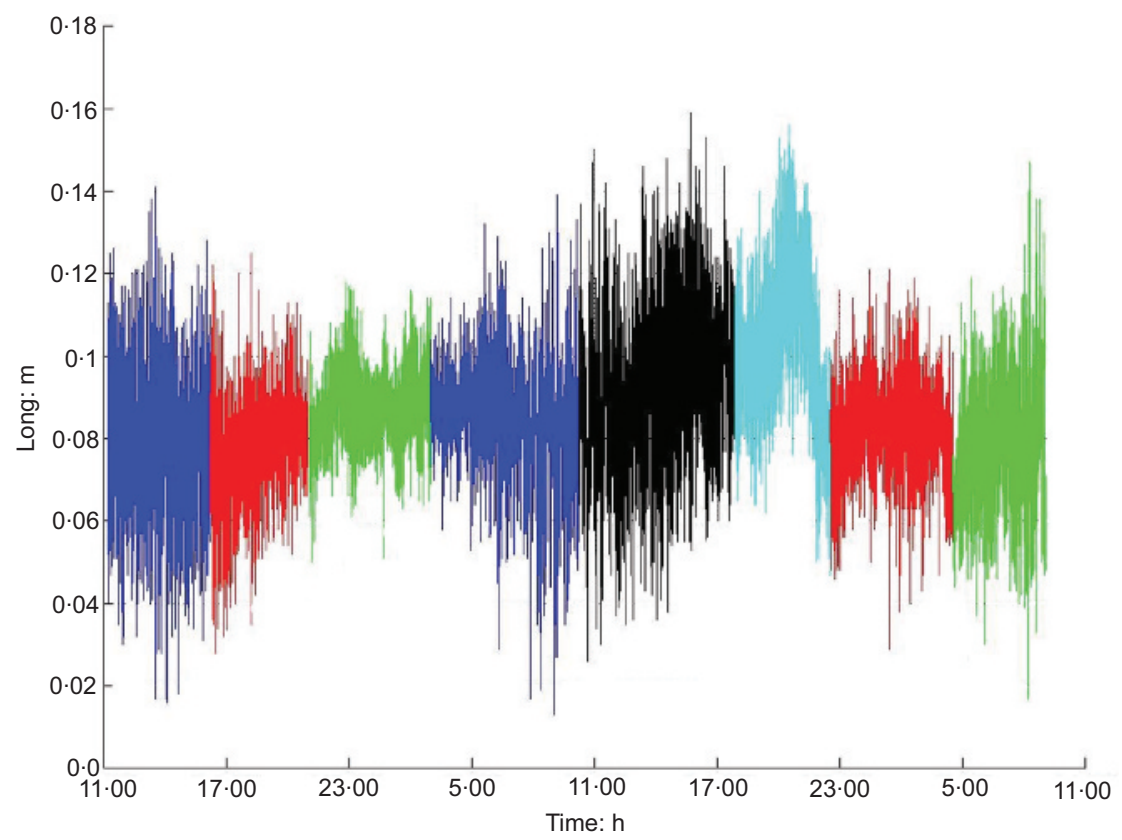

Figure 17. Absolute longitudinal deflections of bridge site $\mathrm{F}$ over the 46-h trial (bridge coordinate system)

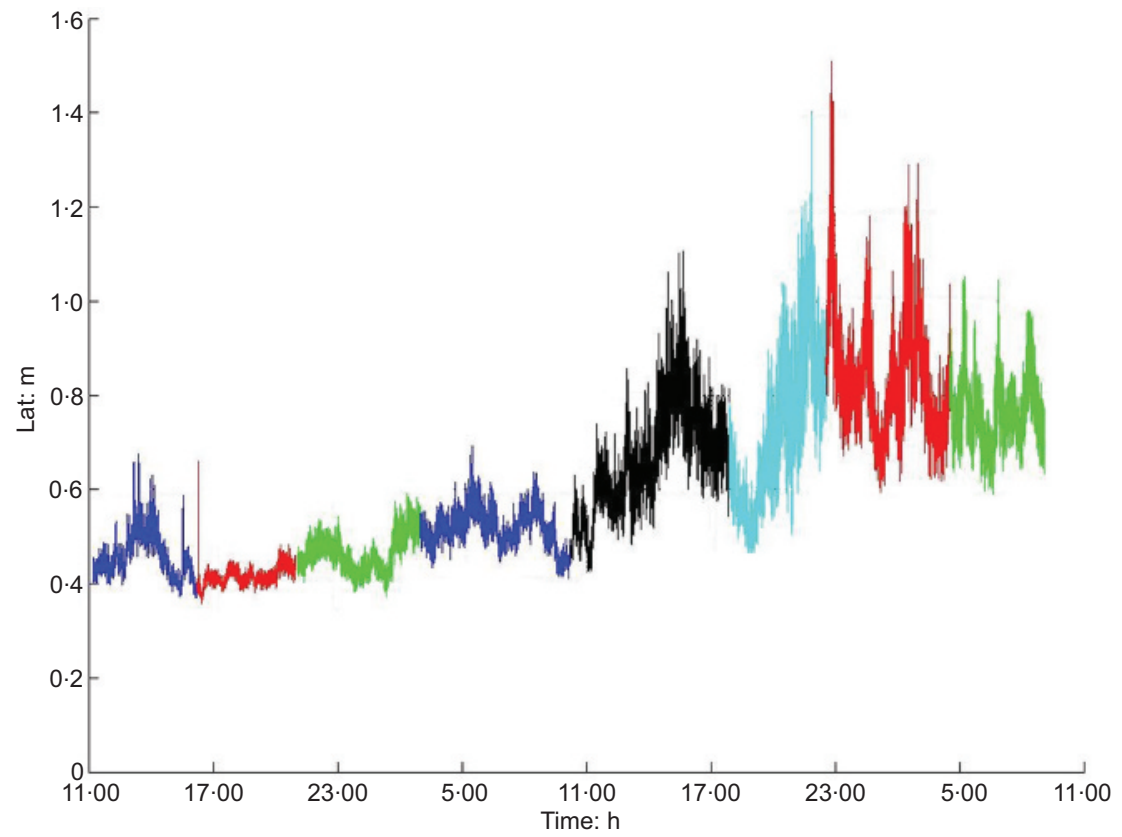

Figure 18. Absolute lateral deflections of bridge site $\mathrm{F}$ over the 46-h trial (bridge coordinate system) 


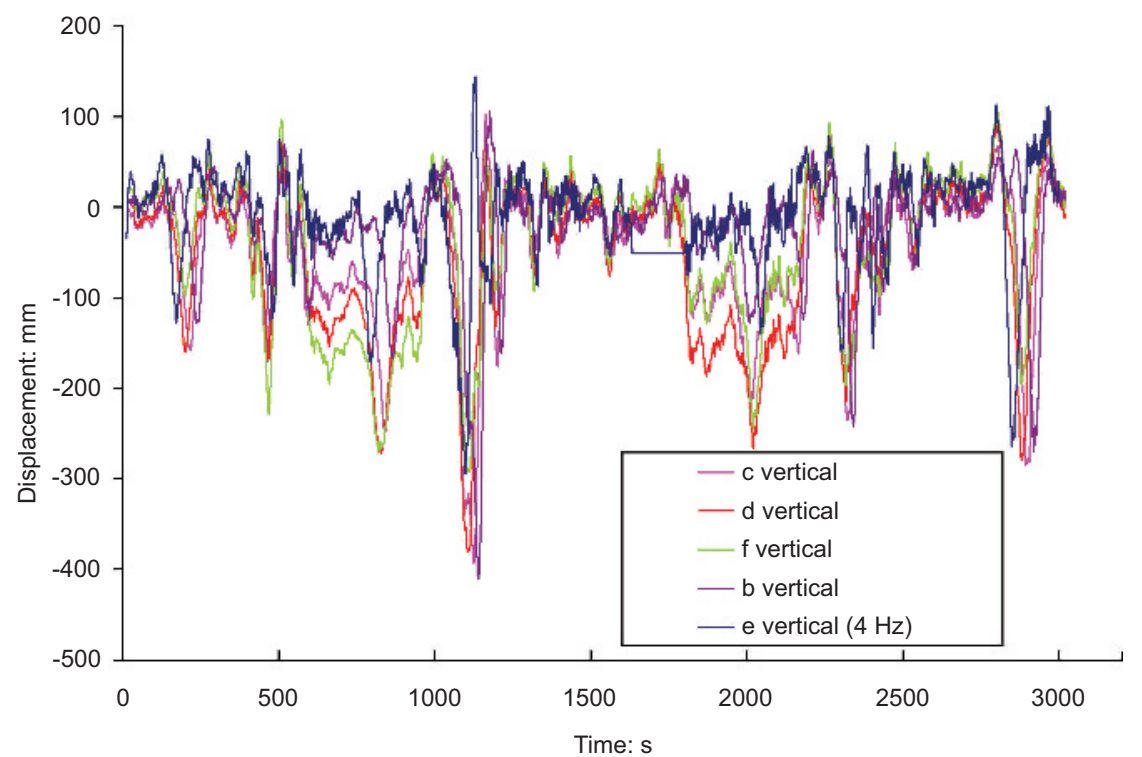

Figure 19. Vertical deflections of the bridge during the 40-t lorry trials

trials are illustrated in Figure 19, while Figure 20 illustrates the final manoeuvre ( $d$ above). The reader should note that vehicles travel on the left-hand side of the road in the UK. The graph also shows the position of the lorries at any time - for example, midspan, north tower, etc.
Three main phenomena are evident in Figure 20. First, the deflections at each GPS receiver site are offset from each other. Second, the GPS receivers located at sites D and F, both at midspan, deflect by different magnitudes, even though they start off at a similar height. This is due to the torsional movement of

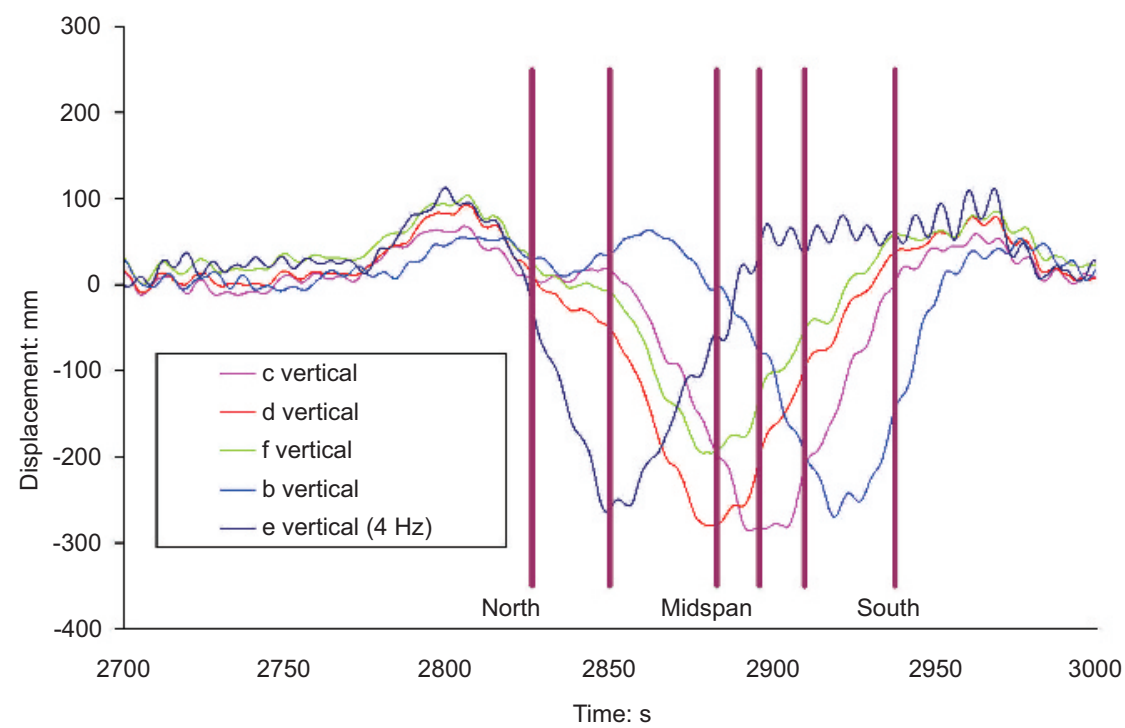

Figure 20. Height deflections during the two 40-t lorries passing over the bridge side by side 


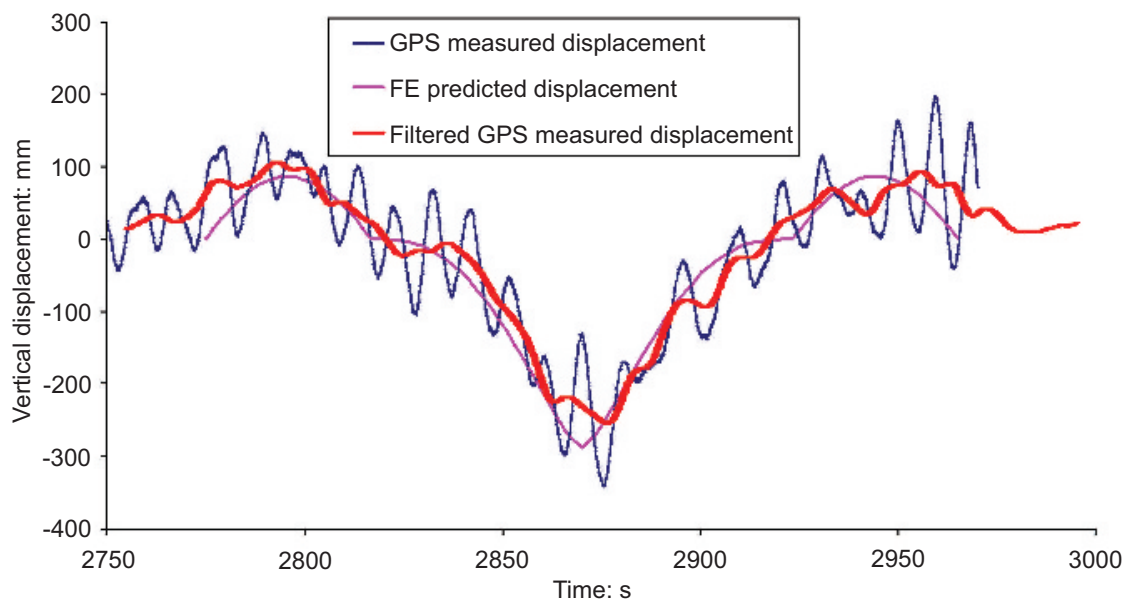

Figure 21. Height deflections compared with predictions from the finite element model

the bridge. The lorries, travelling on the left-hand side of the carriageway from north to south, were in fact travelling on the east side of the bridge. Hence, the eastern side (site D) deflects more than the western side (site F). Third, the reader should note that the bridge consists of three separate spans, each connected through a cable that passes over the top of the towers. As the lorries pass over the northern side span, the loaded hanger cables pull down on the suspension cable, which results in the suspension cable pulling up the main span. This is evident in Figure 20 at approximately $2800 \mathrm{~s}$. The lorries pass into the main span, and their passage over the measured positions is shown in Figure 20 with downward deflection of the main span point $\mathrm{D}$. As the lorries pass into the southerly side span, upward movement of the main span - described above - is observed.
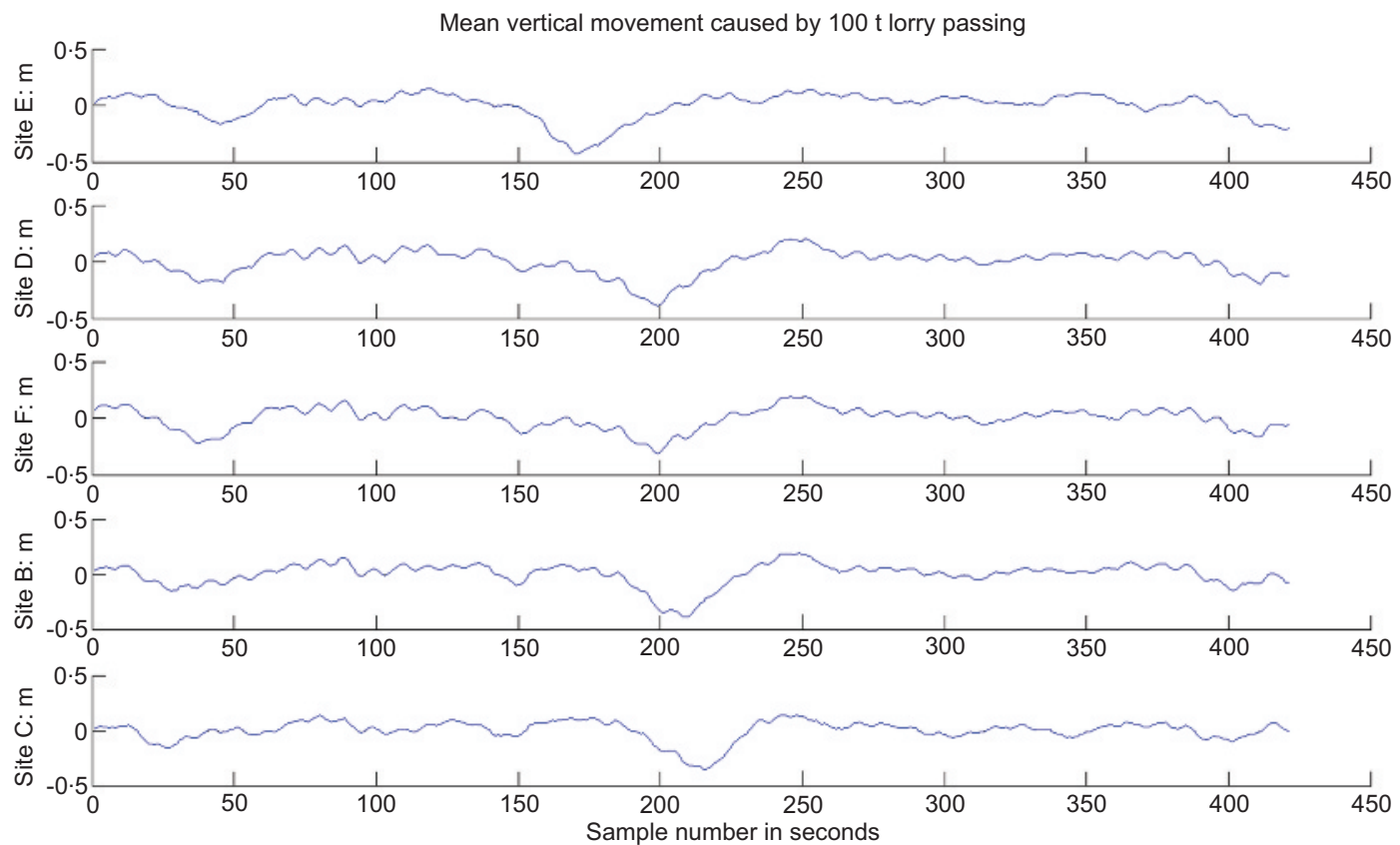

Figure 22. Vertical movement due to 100-t lorry passage 

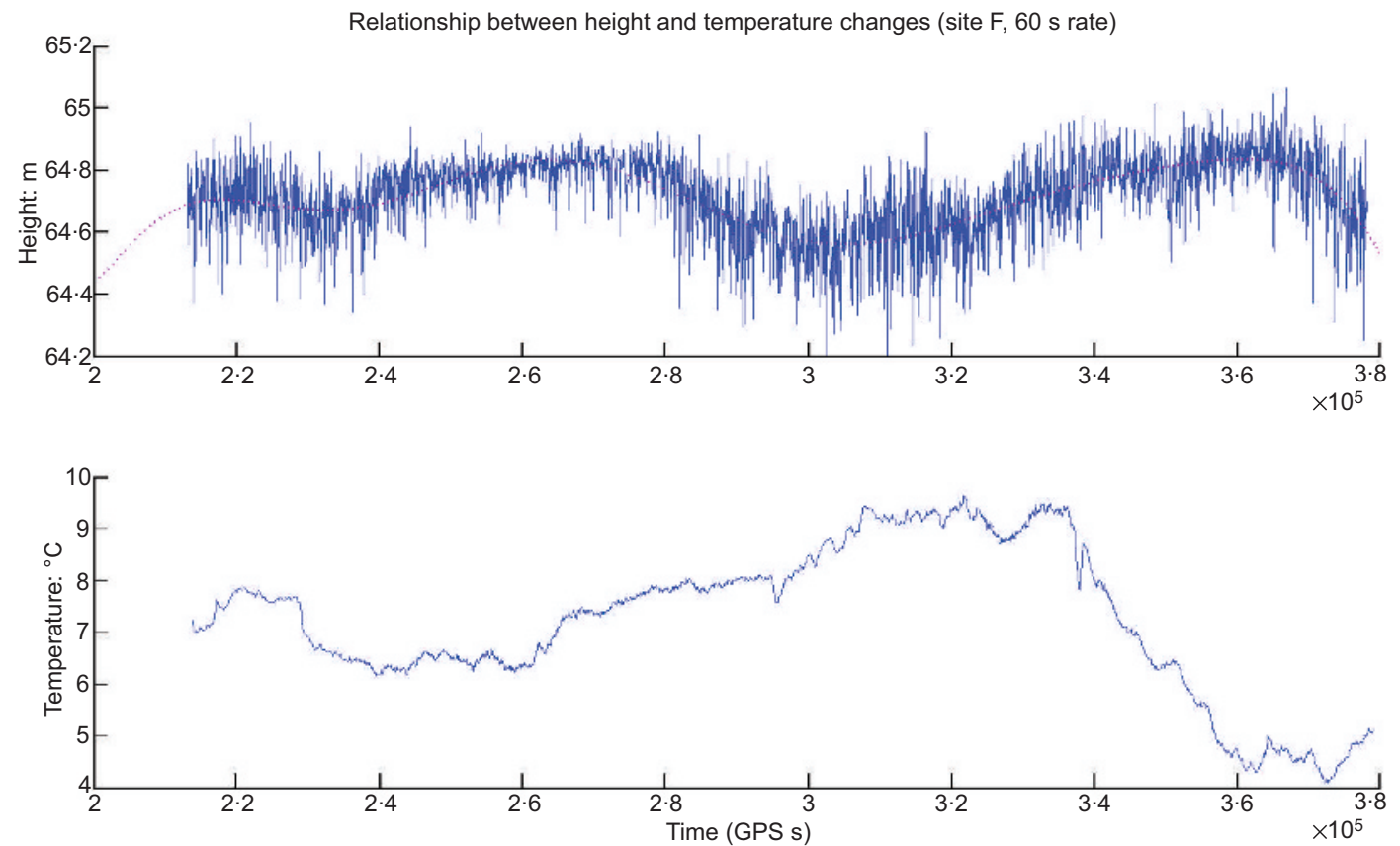

Figure 23. Relationship between air temperature and height

location of the bridge deck at site $\mathrm{F}$ (midspan west)

The results are also compared with those predicted by an existing FEM of the bridge (see Acknowledgements). The FEM used predicted a deflection of $280 \mathrm{~mm}$ under the loading of the two 40-t lorries. The mean deflection of the GPS receiver located at point $\mathrm{D}$ can be seen to match this prediction of $280 \mathrm{~mm}$ extremely well in Figure 20. Further to this, Figure 21 compares the actual measurements at location $\mathrm{D}$, as well as a filtered version of the GPS results using a moving average filter of 100 samples, as well as the FEM results. The moving average filter is used to reduce the higher frequency vibrations, leaving behind the deformations caused by the lorries' mass. Again, it is evident from Figure 21 that there is a very good correlation between the actual and predicted data.

\subsection{Other measured deflections}

During the trial period a 100-t lorry passed over the bridge. The lorry was precisely weighed and this section of the data was analysed in more detail. Figure 22 illustrates the height component of all the bridge deck GPS receivers. It can be seen that the bridge deflects by approximately $40 \mathrm{~cm}$, and that the maximum deflections at each point are offset from each other along the bridge.

Figure 23 illustrates the clear relationship between the air temperature and height deflections at site F. Similar relationships have been shown elsewhere for the Humber Bridge (Roberts et al., 2008). Changes in temperature will significantly affect cable lengths and thus the vertical position of the bridge's deck.

This shows the relationship over a temperature change of approximately $5.5^{\circ} \mathrm{C}$. In reality over a year, the air temperature at this location could well change from $-10^{\circ} \mathrm{C}$ to $+30^{\circ} \mathrm{C}$, and hence a larger vertical change could be expected. This demonstrates the capability of GPS for monitoring the longterm response caused by the ambient loading.

For completeness, Figure 24 shows a typical relationship between the wind speed and the lateral movement of the structure. There is a good correlation between the two.

\subsection{Measured frequencies}

The position of a structure in $3 \mathrm{D}$ coordinates at precise and synchronised times is available from the GPS results, mainly measured at frequencies of at least $10 \mathrm{~Hz}$ in this trial. It is thus possible to extract structural frequencies below $5 \mathrm{~Hz}$. Figure 25 shows the natural frequencies extracted from vertical coordinates at site F, midspan west using MATLAB code. The upper plot is from the vertical displacement data at site $\mathrm{F}$ (midpoint west). The frequency response is significant at $0 \cdot 1055 \mathrm{~Hz}$ and $0.2689 \mathrm{~Hz}$. This is similar to those of similar sized bridges such as the Tsing Ma Bridge in Hong Kong and the Humber Bridge in the UK. The lower plot looks at the frequency of the difference between midspan east and west - thus amplifying the 

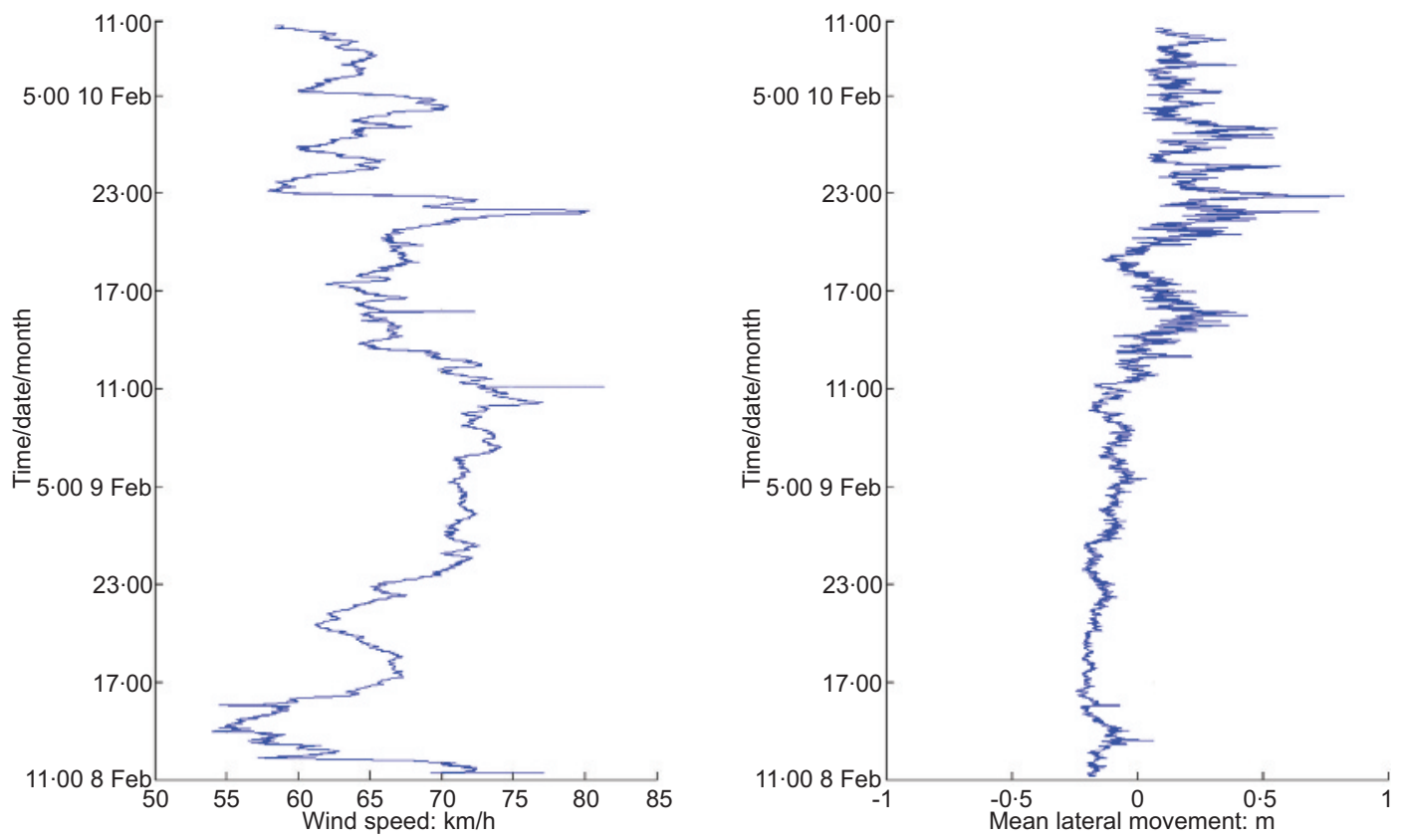

Figure 24. Wind speed and lateral displacements experienced by the bridge over the trial period

torsional response about the longitudinal axis. The frequency response at $0.2689 \mathrm{~Hz}$ is more clearly shown as the lowest torsional frequency, and so it may be deduced that $0.1055 \mathrm{~Hz}$ is the lowest vertical frequency - a period of approximately $9 \cdot 5 \mathrm{~s}$. This correlates well with the data shown in Figure 21, in which the unfiltered signal can be seen to be close to oscillatory at about this period with significant displacements about the mean.
This ties in well with in situ observations made by the authors with the naked eye when a 'rippling' effect on the deck surface was observed.

A detailed assessment has focused on the different time periods for which data were collected and any changes in observed behaviour. Full detail has been presented by Atkins (2006). A
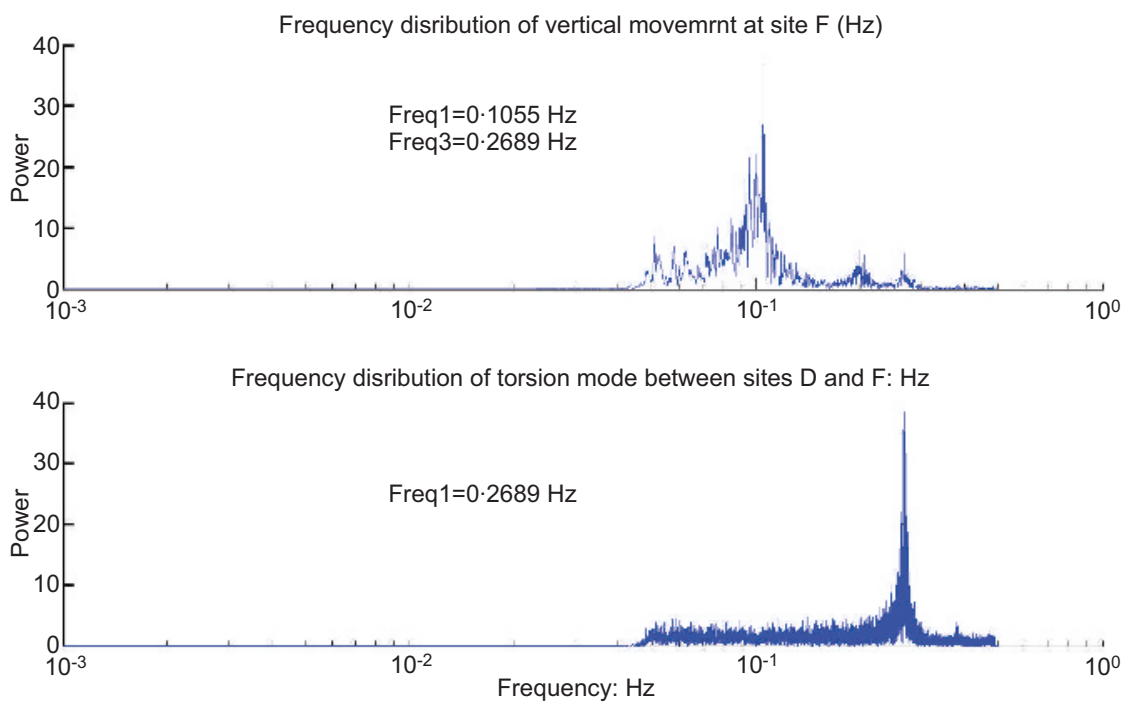

Figure 25. Flexural and torsional frequency response of the bridge 


Mid span E
Mid span W
Mid span E-W
3/8 Span
1/4 Span

Table 2. Frequencies $(\mathrm{Hz})$ detected for 'quiet' and 'busy' periods

$\begin{array}{ll}0 \cdot 1041 & 0 \cdot 1026 \\ 0 \cdot 1041 & 0 \cdot 1026 \\ 0 \cdot 2699 & 0 \cdot 2684 \\ 0 \cdot 1040 & 0 \cdot 1027 \\ 0 \cdot 1041 & 0 \cdot 1027\end{array}$

summary of the data for natural frequency is shown in Table 2, and shows a very good correlation between the different sites, but significantly different natural frequencies for busy and quiet periods. This is to be expected for such suspension structures, as the mass of vehicles traversing the bridge during a busy period will add significantly to the vibrating mass while having no effect on the structural stiffness.

\section{Further observations}

The focused objective of the study, of which the GPS trial was part, was not related to any potential condition monitoring of the bridge - in fact it was associated with enhanced knowledge of precise positions on the bridge at various times. The good offices of the FETA, along with support from the authors' universities enabled a lengthier study to be conducted. However, one of the key advantages of using GPS is the relative ease of implementation achieved on structures such as long-span bridges where alternative surveying methods may be problematical.

Opportunities to carry out GPS-based assessments would lead to more information about the state of key infrastructure projects, and improved knowledge of 'as-built' or in-service performance. This then provides a datum against which future reliability assessments can be made. Issues such as long-term movement (such as has been demonstrated with dams) can be readily assessed, while the combination of high precision and high frequency gives truly four-dimensional (4D) measurements.

The measurements can be taken over short periods in intermittent campaigns, and would be very repeatable if housings for antennas were fitted $a b$ initio and remain in place. Currently, GPS equipment is not cheap, and maintaining it in position on a longer-term basis would not be possible (when trials are carried out in publicly accessible spaces we currently require a person to stay with each station at all times for security purposes, and are indebted to the many students and colleagues who have helped us in this task). Conversely, unit costs could be significantly reduced if teams were established to carry out this work on a rota basis over several infrastructure sites.

Are the data useful? The three trials on public infrastructure for which results have been produced (the Forth Road Bridge is the third) have been funded by industry. In each case the results have been accepted as meeting the three different briefs. The potential for a longer-term monitoring campaign has been demonstrated, and further work has been commissioned by others responsible for the condition of the infrastructure.

\section{Conclusions}

The trials have shown that GPS gives the magnitude and frequencies of the bridge's deflections in 3D. This is possible at a rate of up to $10 \mathrm{~Hz}$, and all the results are synchronised to each other - essentially providing a 4D assessment. Although the trials were carried out in a post-processing manner, it is possible to have carried out these trials in real time, as discussed by Dodson et al. (2004). While real time processing is possible, establishing real time communications was beyond the scope of this trial.

The paper not only illustrates the technique, but analyses only a small portion of the vast amount of data gathered during the trials, sufficient to demonstrate the accuracy and repeatability of the procedure. The challenge for the synthesis of such large datasets for useful structural health monitoring has been recognised, but the authors would argue that accurate and absolute position data are an essential element of any assessment, particularly when they can be allied to load data and predictive models.

The results have been compared with displacement data available from the FEM of the bridge, and show agreement.

The GPS procedures described provide a basis for structural monitoring systems when used in conjunction with predictive models. Real GPS data from specific points can validate such models and assess as-built and in-service behaviour. It has been demonstrated that relatively small changes in mass, in this case from traffic load, can be detected as changes in natural frequency. It is reasonable to assume that changes in stiffness could equally well be detected. If the structure were to deteriorate over a period of many years under normal load actions or as a result of any specific mishap that should occur, then this may well be identified through the use of GPS as the reference satellites will provide a stable datum. 


\section{Acknowledgements}

The trial reported in this paper was funded by the Forth Estuary Transport Authority. The authors gratefully acknowledge support from staff and researchers at the IESSG and FETA.

The authors would like to acknowledge the help of Colin Clark of W.A. Fairhurst and Partners for assistance in providing the displacement result from the FEM.

\section{REFERENCES}

Anderson JK, Hamilton JAK, Henderson W, et al. (1965) Forth Road Bridge. Proceedings of the Institution of Civil Engineers 32(3): 321-512.

Ashkenazi V and Roberts GW (1997) Experimental Monitoring the Humber Bridge with GPS. Proceedings of the Institution of Civil Engineers - Civil Engineering 120(4): 177-182.

Ashkenazi V, Dodson AH, Moore T and Roberts GW (1996) Real time OTF GPS monitoring of the Humber Bridge. Surveying World 4(4): 26-28.

Atkins C (2006) Deflection Monitoring of the Forth Road Bridge and Wilford Footbridge using GNSS. MSc thesis, University of Nottingham, UK.

Barnes J, Rizos C, Wang J, et al. (2003) The monitoring of bridge movements using GPS and pseudolite. In 11th International Symposium on Deformation Measurements. International Federation of Surveyors (FIG), Santorini, Greece, 25-28 May 2003, pp. 563-572.

Brown CJ, Karuna R, Ashkenazi V, Roberts GW and Evans R (1999) Monitoring of structures using GPS. Proceedings of the Institution of Civil Engineers - Structures 134(1): 97 105.

Brown CJ, Roberts GW and Meng X (2006) Developments in the use of GPS for bridge monitoring. Proceedings of the Institution of Civil Engineers - Bridge Engineering 159(3): 117-119.

Brown CJ, Meng X and Roberts GW (2008) Deflection monitoring of bridges: a case study of the Forth Road Bridge. In Bridge Maintenance, Safety, Management, Health Monitoring and Informatics (IABMAS08) (Koh H$\mathrm{M}$ and Frangopol D (eds)). Balkema Press, Taylor and Francis, London, UK, p. 413.

Brownjohn JMW (2005) Lateral loading and response for a tall building in the non-seismic doldrums. Engineering Structures 27(12): 1801-1812.

Brownjohn JMW, Rizos C, Tan GH and Pan TC (2004) Real-Time Long-Term Monitoring of Static and Dynamic Displacements of an Office Tower, Combining RTK GPS and Accelerometer Data. In Proceedings of the 1st FIG International Symposium on Engineering Surveys for Construction Works and Structural Engineering, Nottingham, UK, 28 June-1 July 2004.

Cosser E, Roberts GW, Meng X and Dodson AH (2003) The Comparison of Single Frequency and Dual Frequency GPS for Bridge Deflection and Vibration Monitoring. In Proceedings of the Deformation Measurements and Analysis, 11th International Symposium on Deformation Measurements. International Federation of Surveyors (FIG), Santorini, Greece, May 2003.

Dan D, Sun L, Meng X and Xie D (2008) The statistical investigation on one year GPS monitoring data from Donghai Bridge Health Monitoring System. In Bridge Maintenance, Safety, Management, Health Monitoring and Informatics (IABMAS08) (Koh H-M and Frangopol D (eds)). Balkema Press, Taylor and Francis, London, UK.

Dodson AH, Meng X, Andreotti M, Roberts GW and Walker M (2004) Design and realization of RTK GPS over internet for a 'smart bridge'. Transactions of the Journal of Nanjing University of Aeronautics and Astronautics 22(2): 91-97.

Fujino Y, Murata M, Okano S and Takeguchi M (2000) Monitoring system of the Akashi Kaikyo Bridge and displacement measurement using GPS. Proceedings of SPIE 3995: 229-236.

Guo J, Xu L, Dai L, et al. (2000) Application of the real-time kinematic global positioning system in bridge safety monitoring. ASCE Journal of Bridge Engineering 10(2): 163-168.

Hancock C, Roberts GW and Taha A (2009) Satellite mapping in cities: how good can it get? Proceedings of the Institution of Civil Engineers - Civil Engineering 162(3): 122-128.

Hide C, Blake S, Meng X, et al. (2005) An investigation in the use of GPS and INS sensors for structural health monitoring. In Proceedings of ION GNSS, Long Beach, California, 1316 September 2005.

Hofmann-Wellenhof B, Lichtenegger $\mathrm{H}$ and Collins J (2001) GPS Theory and Practice, 5th edn. Springer, New York, USA.

Karuna R, Yao MS, Brown CJ and Evans RA (1997) Modelling and analysis of the Humber Bridge. In IASS International Colloquium on Computation of Shell and Spatial Structures (ICCSS'97), Taiwan, November 1997.

Karuna R, Yao MS, Brown CJ and Evans RA (1998) In-service modelling of the Humber Bridge. In IABSE Symposium 'Long Span and High-Rise Structures', Kobe, 2-4 September 1998, pp. 441-446.

Leick A (2004) GPS Satellite Surveying. John Wiley, Hoboken, NJ, USA.

Meng X (2002) Real-time deformation monitoring of bridges using GPS/accelerometers. PhD thesis, University of Nottingham, Nottingham, UK.

Meng X, Roberts GW and Dodson AH (2005) GNSS for structural deflection monitoring: implementation and data analysis. (Chang FK (ed)). Structural health monitoring 2005: advancements and challenges for implementation. In Proceedings of 5th International Workshop on Structural Health Monitoring. Stanford University, USA, 12-14 September 2005.

Meng X, Dodson AH and Roberts GW (2007a) Detecting bridge 
dynamics with GPS and triaxial accelerometers. Engineering Structures 29(11): 3178-3184. ISSN: 01410296.

Meng X, Brown CJ, Roberts GW and Andrew A (2007b) Using GPS to measure the response of the Forth Road Bridge to wind and temperature loading. Hong Kong Institution of Engineering Surveyors. Journal of Geospatial Engineering 9(1-2): 1-11.

Ordnance Survey (2008) Welcome to the OS Net Free Services. See http://www.ordnancesurvey.co.uk (accessed 25/11/ 2008).

Roberts GW, Meng X, Dodson AH and Cosser E (2002) Multipath mitigation for bridge deformation monitoring. International Journal of GPS 1(1): 25-33. ISSN 1446-3156. See http:// www.cpgps.org/journal/journal.html (accessed 20/04/2009).

Roberts GW, Meng X and Dodson AH (2004) Integrating a global positioning system and accelerometers to monitor the deflection of bridges. American Society of Civil Engineers. Journal of Surveying Engineering 130(2): 65-72.

Roberts GW, Meng X, Brown CJ and Dallard P (2006) GPS measurements on the London Millennium Bridge. Proceedings of the Institution of Civil Engineers - Bridge Engineering 159(4): 153-161.

Roberts GW, Meng X and Brown CJ (2008) Research into the use of GNSS to monitor the deflections of suspension bridges, and the role of the FIG in deformation monitoring of bridges. In Bridge Maintenance, Safety, Management, Health Monitoring and Informatics (IABMAS08) (Koh H-M and Frangopol D (eds)). Balkema Press, Taylor and Francis, London, UK, p. 412.

Wong K-Y (2007) Design of a structural health monitoring system for long-span bridges. Structure and Infrastructure Engineering 3(2): 169-185.

\section{WHAT DO YOU THINK?}

To discuss this paper, please email up to 500 words to the editor at journals@ice.org.uk. Your contribution will be forwarded to the author(s) for a reply and, if considered appropriate by the editorial panel, will be published as discussion in a future issue of the journal.

Proceedings journals rely entirely on contributions sent in by civil engineering professionals, academics and students. Papers should be 2000-5000 words long (briefing papers should be 1000-2000 words long), with adequate illustrations and references. You can submit your paper online via www.icevirtuallibrary.com/content/journals, where you will also find detailed author guidelines. 